\title{
How blood was let in the sixteenth century: Jacques Guillemeau, La Chirurgie Françoise... 1594
}

Jacques Guillemeau (1550-1612), born in Orleans into a family of surgeons, was the most eminent pupil of the greatest surgeon of the sixteenth century, Ambroise Paré. He was Paré's friend as well as his pupil; in his dedication to Paré in his book on diseases of the eye he says '...I would like to let everyone know how indebted I was to you that I had been taught for eight years in your house' and signs himself 'your affectionate friend and servant'. ', Though gushing, as were many dedications of the period, this has the ring of truth; it seems that Guillemeau did indeed live with Paré and his family. Further, we know that after Parés death, Guillemeau saved the life of one of Parés daughters, Anne Simon, who had a serious intrapartum haemorrhage, by delivering her baby in 1599 'as he had seen his master do.' ${ }^{2}$ Guillemeau was surgeon-inordinary to three French kings (though never, it seems, principal surgeon, unlike Paré) and was Provost of the Confrèrie de Saint-Côme et Saint-Damien - usually abbreviated to Collège de St Côme - which was later renamed the Collège de Chirurgie. Like his master, Guillemeau followed the armies and was an experienced battlefield surgeon. He is now remembered mainly as the author of an influential text on obstetrics De L'Heureux Accouchement des Femmes (1609) later translated into English as Childbirth, or The Happy Delivery of Women (1635). But he also wrote a number of other surgical works including the rather unusual Chirurgie Françoise of 1594 which we consider here., ${ }^{3, \dagger}$

The Chirurgie announces itself as an illustrated catalogue of all the principal surgical instruments of its time, and indeed, it is that. It includes quite detailed descriptions of the instruments shown in its engraved plates but it also has a number of chapters of text describing some of the operations in which they were used as well as one on medico-legal reports and another, 'Apology for Surgeons', in which Guillemeau seeks to defend them from blame for the death of patients with severe afflictions. The illustrations are full-page copperplate engravings of good quality and the title-page is a fine example of excellent engraving showing examples of surgical procedures in some detail. Though much of the content of the Chirurgie is, not surprisingly, similar to that of Paré's works, the style is very different. Where Paré is personal, circumstantial and deeply engaged he is at the centre of the many 'histories' he relates - Guillemeau is more general and more detached and his prose is measured where Paré's is flamboyant. Guillemeau had a distinguished career in surgery, though he died much younger than his master. Like Paré, he was surgeon to several French kings, but unlike him, he held what today might be called an academic post, though it is doubtful if the Faculté de Médecine would have so regarded it - that of Provost of the College de St Côme. And, like Paré, he had his battles with the physicians of the Paris Faculté. In spite of this, his son Charles became a physician and was doyen (dean) of the Faculté de Médecine in 1634-5.

The organisation of the practice of surgery in Paris in the sixteenth century was in a state of flux. Effectively, there were two groups, the barbersurgeons ('surgeons of the short robe') who practised both trades and the 'surgeons of the long robe' who distanced themselves from their simpler brothers. For all that, even the 'long robes' often still called themselves barber-surgeons though they certainly did no barbering. This might be because that form may still have been used in the oath they took. By the sixteenth century the surgeons of the long robe were members of the Collège de St Côme which was the name taken by the very much older Confrèrie de Saint-Côme et Saint-Damien whose origins go back at least to the thirteenth century. In the sixteenth century these collegians were trying to have their trade accepted as a profession forming part of the art of medicine - an acceptance that was vigorously opposed by the physicians who formed the Faculte de Médecine. For their part, the surgeons set up a grade of Maitre Chirurgien, admission to which was by examination by the Masters of the College. In 1554 Paré failed this examination on account of his barbarous Latin - which is quite credible since he knew no Latin, as he himself tells us - and also his lack of experience in surgery, which is emphatically not credible at all. ${ }^{\dagger \dagger}$ But, since he had powerful senior surgical friends, he was admitted anyway and became a 'doctor' within the year. ${ }^{2}$ Both Paré and Guillemeau were targets of the physicians' wrath and battles were fought in the law courts as well as in print. The surgeons' position was weakened by the lack of their early statutes which seem to have been lost. 
There was an unedifying episode in which Paré and Guillemeau, with a couple of other surgeons, jointly opposed their brothers who, they believed, were engaged in producing a set of forged statutes.

\section{THE CHIRURGIE FRANÇOISE}

The title-page is perhaps the book's most interesting illustration. It shows six surgical procedures (or groups of them); the top panel is labelled chirurgia quam citissime administranda, 'surgery that must be carried out as soon as possible' - emergency surgery. This panel shows, on the right, treatment of a skull fracture by trepanning and, on the left, among other injuries, the

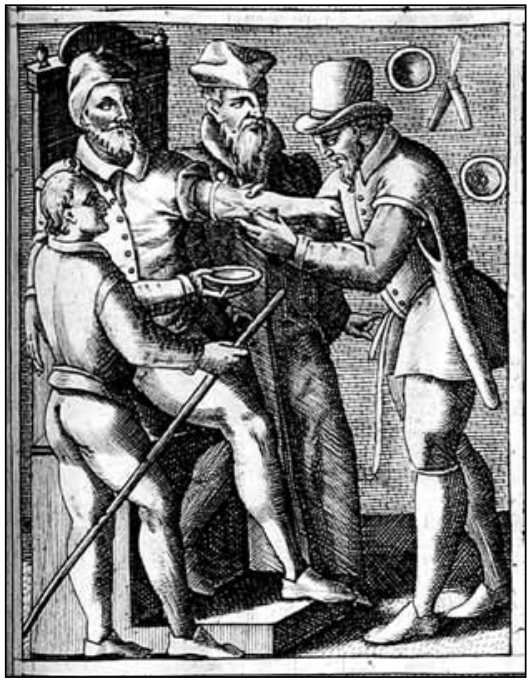

FIGURE I The procedure of bloodletting. From the title-page of Guillemeau's Chirurgie Françoise. precepts it also followed that different veins had to be used for different organs and at different stages of the disease. Though the decision to bleed, how much blood to remove and from which vein, was the physician's to make (except sometimes in purely surgical conditions) it was the surgeon who carried out the procedure. The physician himself might, or might not, be present at the procedure; no doubt this depended somewhat on the patient's social status - and the depth of his purse. Guillemeau begins by emphasising this and saying it is no part of his intention to describe the physician's work but just to set out how to carry out the procedure well. He says that 4 I veins are available for bloodletting removal of an arquebus ball from the thigh using an instrument specially designed for the purpose. In the centre-left panel is an illustration of bloodletting; on the centre-right, one showing couching of a cataract. At the bottom we have amputation of a leg and an arm on the left and reduction of a dislocation of the shoulder and treatment of a fracture of the leg on the right. The illustration of bloodletting is particularly interesting because, most unusually, Guillemeau devotes three chapters of text to this procedure. I shall concentrate on this since they describe such a common procedure so rarely dealt with in detail in most books of the time.

\section{Bloodletting}

Though the practice of bleeding for almost any imaginable malady long outlived purely Galenic medicine, in the sixteenth century and particularly in Paris, practice was firmly based on Galenic theory; iatrochemistry was becoming popular - to the fury of the Paris Faculté - but that need not concern us here. Bleeding, along with purging, vomiting and, occasionally, induced sweating, was the means of removing excess or disordered humours which were believed to be the causes of disease. There was, of course, no conception of blood circulation and each part of the body could have its own 'disordered' blood. Bleeding followed one of two procedures: 'revulsion' or 'derivation'. In the former, to be exercised early in the malady before the humours had settled in any one area, or as a prophylactic, blood was withdrawn from a site as far as possible from the diseased organ or area. Later, 'derivation' removed blood from as close as possible to the site of disease to void the local malign humours. Deciding which method to use was part of the physician's art and, of course, since all depended on judgment made from no objective evidence, wild disagreement was possible - and common. From these and provides an illustration marking these and giving their names because, he says, the surgeon must know them apart and not mistake one for another. The list of vein-organ associations is long; taking only the arm as example, the cephalic vein was appropriate for headache, sore eyes, diseases of the head in general, and affections of the throat. The basilar vein was used for 'obstructions of the liver', inflammation anywhere and for disease below the head while the median was suitable for maladies anywhere. But the surgeon might be required to open a vein almost anywhere; temple, several sites on the nose, under the tongue, hand, even a haemorrhoidal vein. Some of them must have been rather difficult to bleed from.

Having dealt with where to bleed, Guillemeau turns to how to do it - and deals principally with bleeding from the cubital fossa which he says is much the commonest site - perhaps not surprisingly. From Guillemeau's account it seems that the surgeon had a good deal of discretion over when and how the prescribed quantity of blood was withdrawn - for example, in a single bleeding or in several sessions spread over hours or days - and such procedural details as whether the patient should be seated or lying in bed. He makes it clear that the surgeon's decision on this must take into account the patient's state - robust or feeble - as well as the quantity of blood to be removed. In the plate (Figure I) we see the seated patient surrounded by three figures: the physician in cap and gown, the surgeon carrying out the incision and an assistant holding the collecting bowl in one hand and a staff resembling a broom handle in the other.At the top right is shown the lancet or fleam used to incise the vein and a pair of bleeding bowls. It is interesting that the fleam - which is shown in more detail in one of the plates of instruments - is identical in design to that still in use in nineteenth-century Britain. The leaf-shaped blade is 
pivoted at its lower end by a pin passing through the two leaves of the handle and the blade folds between these leaves when not in use. I have a pair of fleams in a silver case hallmarked in London in 1814-15 in which the handles consist of two pieces of tortoiseshell between which the blade folds. They look exactly like that illustrated by Guillemeau.

There is a great deal of practical detail about just how to carry out phlebotomy. It is an interesting mixture of instructions that would be completely appropriate for instructing a phlebotomist today - taking into account that using a knife to incise a vein is rather different, and rather more risky, than using a needle on a syringe. For example, a ligature was to be used above the bleeding point and this must be neither too tight nor too loose; the vein was to be palpated then steadied with finger or thumb - though holding the instrument in readiness between the lips might, perhaps, now be frowned upon. Avoiding arteries and nerves is enjoined and the advantage for this of the cephalic vein over the median is emphasised. The use of a pressure-dressing over the incision is described though one does not now usually cut a bean in half and place it under the dressing to apply local pressure if haemorrhage is difficult to stop; but we now make a puncture not an incision. This also means that we do not have to decide whether to cut the vein transversely, longitudinally or obliquely - each had its own indications. A small incision was appropriate not only for removing small quantities but also when 'revulsion' was needed-for example to treat haemoptysis or nosebleeds - when the blood must flow slowly and not too much taken because the necessary volume loss has already been accomplished by the disorder itself. Unlike the sixteenth-century surgeon, we do not now have the chance to delight the bystanders by using an oblique incision which, Guillemeau says, 'those standing by find the most elegant method since the blood comes out as it were in a spiral' (whatever that meant). If the blood does not flow promptly the patient is to be given a baton to hold - this is good practice in any case - and asked to grip it firmly or roll it around in the hand. This is the purpose of the broom handle the assistant is holding in the figure. Guillemeau was well aware that some patients feel faint - and even do faint; to avoid this, nervous, feeble or weak patients, or those from whom a large quantity is to be removed, should be bled lying down. If a patient suddenly becomes faint the blood flow is to be stopped at once and the patient put flat on his back, and reassured - because he will soon recover. It is best not to remove too much blood at once, rather to repeat the procedure hours or days later if a large bleed has been prescribed.
Overall, it is perhaps the similarities to modern practice that are more striking than the differences in procedure. For all that their reasons for removing blood were completely different from ours, the technical competence of the practitioners and the clarity of Guillemeau's description are still most satisfying to the reader.

IML Donaldson, Honorary Librarian, RCPE

(email: i.m.I.d@ed.ac.uk)

\section{NOTES}

$\S \quad$ '...ie desirerois faire cognoistre à un chacun, combien ie vous estois redevable, pour avoir esté l'espace de huict ans endoctriné en vostre maison' ref. I sig. ã ij verso. The dedication ends 'vostre tres affectionné Amy \& serviteur, GUILLEMEAU'

$\dagger$ In London in 1631 and 1634 Helkiah Crooke published a superficially similar work ${ }^{4}$ derived avowedly from Paré's writings and illustrated with woodcuts copied from Parés Oeuvres. But Crooke was a physician not a surgeon and is unlikely to have had much - if any - practical experience of the use of the instruments and his book is, as he announces, copied from Paré. Guillemeau, on the other hand, was a very experienced surgeon who, like Paré, had extensive battlefield experience, including, as he laments in his preface, during the bitter French religious wars of the sixteenth century.

It ...questionibus et chirurgicis problematibus illi objectis debiliter et sermone satis barbaro et corrupto respondit. '...he replied to questions and problems in surgery feebly and in barbarous and corrupt language'.Quoted in Le Paulmier.' But he was admitted in deference to Estienne de la Rivière 'on condition that he learn Latin and apply himself to the study of the theory and practice of surgery.'

The question of the authenticity of the statutes is uncertain. Though a set of statutes apparently from I 379 is still extant - the thirteenth century document being missing - these were 'verified and certified' only in $1603^{5}$ and the opposition of the highlyprincipled Paré and a few of his colleagues to those being promulgated in the later sixteenth century must give some cause for doubt. But of the existence from the thirteenth century of the Confrèrie itself there is no doubt.

\section{REFERENCES}

I Guillemeau J. Traité des maladies de l'oeil, qui sont en nombre de cent treize, ausquelles il est suiect. Paris: Chez Charles Massé au Clos Bruneau à l'enseigne de la Pyramide; I585. French.

2 Le Paulmier CS. Ambroise Paré d'après de nouveaux documents découverts aux Archives Nationales et des papiers de famille, par le docteur Le Paulmier. Paris: Charavay Frères; 1884. French.

3 Guillemeau J. La chirurgie francoise recueillie des antiens medicins et chirurgiens avec plusieurs figures des instrumens necesseres pour l'operation manuelle par Jacques Guillemeau d'Orleans, chirurgien du Roy et juré a Paris. Paris: Nicolas Gilles; 1594. French.

4 Crooke H. An explanation of the fashion and use of three hundred and fifty instruments of chirurgery. Gathered out of Ambrosius Pareus and done into English, for the behoofe of young practitioners in chirurgery by HC London. Printed for Michael Sparks; 1634.

5 Nicaise E. Premiers statuts des chirurgiens de Paris. Paris: Félix Alcan; 1893. French. 


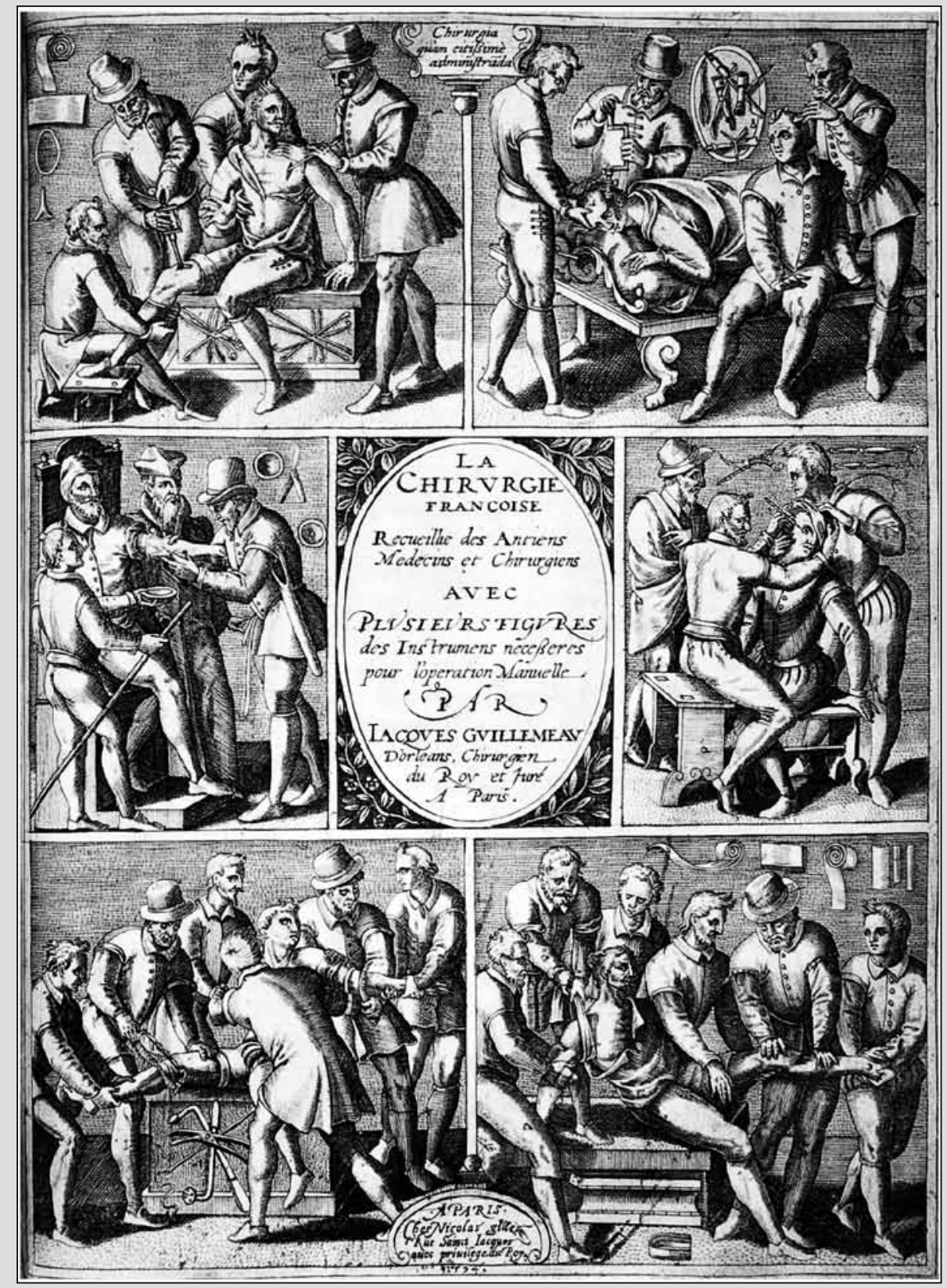

The title page of La Chirurgie Françoise... by Jacques Guillemeau, Paris I594. Top panel: 'chirurgia quam citissime administranda' - emergency surgery; left, removal of arquebus ball from the thigh and other injuries; right, trepannation for skull fracture and dressing of head wound. Middle left, bloodletting. Middle right, couching a cataract. Bottom left, amputation of leg and arm. Bottom right, reduction of dislocated shoulder and treatment of fracture of leg. See the article on pages 375-7. 